\title{
Formononetin inhibits colon carcinoma cell growth and invasion by microRNA-149-mediated EphB3 downregulation and inhibition of PI3K/AKT and STAT3 signaling pathways
}

\author{
AI-LEI WANG ${ }^{1,2}$, YONG LI ${ }^{1}$, QUN ZHAO $^{1}$ and LI-QIAO FAN ${ }^{1}$ \\ ${ }^{1}$ Department of General Surgery, The Fourth Hospital of Hebei Medical University, Shijiazhuang, Hebei 050011; \\ ${ }^{2}$ Department of Anus and Intestine Surgery, Tangshan Traditional Chinese Medicine Hospital, \\ Tangshan, Hebei 063000, P.R. China
}

Received August 28, 2017; Accepted February 23, 2018

DOI: $10.3892 / \mathrm{mmr} .2018 .8857$

\begin{abstract}
Formononetin (Form), a phytoestrogen extracted from the roots of Astragalus membranaceus, is one of the fundamental herbs used in traditional Chinese medicine because of its protective effects against certain malignant tumors. However, its role in colon carcinoma cells and the underlying molecular mechanisms have not been completely elucidated. The present study aimed to demonstrate that Form significantly inhibited the proliferation and invasion of the colon carcinoma cell lines SW1116 and HCT116. Mechanistic studies have suggested that Form suppresses colon carcinoma cell growth by downregulating cell cycle-associated protein (cyclin D1) expression and arresting the cell cycle at the $G_{0}-G_{1}$ checkpoint. Further studies revealed that treatment with Form inhibits matrix metalloproteinase (MMP)2 and MMP9 expression. Aditionally, the results demonstrated that Form significantly increased microRNA (miR)-149 expression. Following miR-149 overexpression in SW1116 and HCT116 cells using an miR-149 mimic, cell viability and Ephrin type-B receptor 3 (EphB3) levels decreased. Furthermore, the inhibitory effects of Form were associated with phosphatidylinositol 3-kinase (PI3K)/protein kinase B (AKT) and signal transducer and activator of transcription 3 (STAT3) signaling pathways. These results indicated the suppressive effect of Form on colon carcinoma cell proliferation and invasion, possibly via miR-149-induced EphB3 downregulation and the inhibition of the PI3K/AKT and STAT3 signaling pathways. Overall, Form may be used as a novel candidate for the clinical treatment of colorectal cancer in the future.
\end{abstract}

Correspondence to: Dr Yong Li, Department of General Surgery, The Fourth Hospital of Hebei Medical University, 12 Jiankang Road, Shijiazhuang, Hebei 050011, P.R. China

E-mail: li_yong_hbth@126.com

Key words: formononetin, colon carcinoma cell, proliferation, invasion, microRNA-149, signaling pathways

\section{Introduction}

Colorectal carcinoma (CRC) is the third most prevalent cancer globally, the incidence rate of which increases with advancing age (1). Despite advances in chemotherapy, radiotherapy and novel drug development, the prognosis in patients with CRC remains poor. Furthermore, the occurrence of severe side effects and toxicities limit the existing therapeutic regimens. Therefore, alternative medications with pronounced effectiveness and low-toxicity are necessary $(2,3)$.

Formononetin (Form) is an O-methylated isoflavone phytoestrogen obtained from the root of Astragalus membranaceus, an essential herb used in Chinese medicine for $>2,000$ years which offers various pharmacological effects including inhibition of tumor cell proliferation, migration and invasion $(4,5)$. Furthermore, a previous study indicated that Form controlled CRC progression without causing significant toxicity in drug-treated animals, with no mortality or decline in body weight. In addition, it did not exert any neutropenic effects on drug-treated animals (6). The discovery of low-toxicity Form, which possesses potential for cancer chemoprevention or treatment is essential for the development of colon cancer therapy.

MicroRNAs (miRs) are endogenous, small, single-stranded and non-coding RNAs that function as gene expression repressors by binding to target sites in the 3'-untranslated regions of messenger RNA (mRNA) (7). These miRs can be categorized as oncogenes or tumor suppressors and by targeting various transcripts, they participate in the proliferation, apoptosis, differentiation, and invasion processes (8). Recent studies have suggested that Form inhibits various human cancers via miR regulation. For example, it inhibited human bladder cancer cell proliferation and invasiveness (9) and induced apoptosis in the human osteosarcoma cell line U2OS (10) and breast cancer cells (11) via miR-21 or miR-375 regulation. Another recent study has demonstrated that EphB3-targeted miR-149 regulation serves a role in the migration and invasion of HCT116 and SW620 cells (12). However, whether Form inhibits colon carcinoma cell proliferation and invasion by EphB3-targeted miR-149 regulation has not yet been investigated.

Previous studies have demonstrated that Form induces growth inhibition and promotes caspase-dependent apoptosis, 
which involves the inhibition of antiapoptotic proteins including B-cell lymphoma-2 and B-cell lymphoma-extra large, and the activation of the novel proapoptotic protein nonsteroidal anti-inflammatory drug activated gene-1 in human colon cancer cells (13). In addition, Form inhibits angiogenesis and tumor cell invasion involving matrix metalloproteinase (MMP) inhibition in human colon cancer cells (14). However, detailed investigations on Form-induced proliferation and invasion of colon carcinoma as well as its underlying molecular mechanisms still remain limited.

Accumulating evidence indicates that Form may serve as an agent that can deal with several cancer types including breast (15), bladder (16) and prostate (15) cancer. Treatment of these cancer cells with Form significantly decreased the cyclin D1 protein and gene expression, which was demonstrated to be associated with phosphatidylinositol 3-kinase (PI3K)/protein kinase B (AKT), extracellular signal-regulated kinase (ERK), or signal transducer and activator of transcription 3 (STAT3) signaling pathways. However, which signaling pathway is involved in the Form-mediated antitumor effects on human CRC cell growth and invasion remains unclear. The present study aimed to test the effects of Form on colon cancer cell proliferation and invasion and further dissected the molecular mechanisms underlying the regulation of cell proliferation and invasion. The present study also demonstrated for the first time to the best of the authors' knowledge that Form suppresses colon carcinoma cell growth and invasion via the miR-149-mediated EphB3 downregulation and the inhibition of the PI3K/AKT and STAT3 signaling pathways.

\section{Materials and methods}

Reagents. Form (purity $>98 \%$ ), provided by Phytomarker, Ltd., (Tianjing, China), was verified by high-performance liquid chromatography and its chemical structure is illustrated in Fig. 1A. Form was dissolved in dimethyl sulfoxide (DMSO) as a $200 \mathrm{mM}$ stock solution and stored at $4^{\circ} \mathrm{C}$ for further use.

Cell culture. The human colon carcinoma cell lines SW1116, HCT116 and normal colon epithelial NCM460 cells were obtained from the Cancer Hospital, Chinese Academy of Medical sciences (Beijing, China). The cells were cultured in Dulbecco's modified Eagle's media (Hyclone; GE Healthcare Life Sciences, Logan, UT, USA) containing 10\% fetal bovine serum (FBS; Hyclone; GE Healthcare Life Sciences), 100 kU/1 penicillin and $100 \mathrm{mg} / 1$ streptomycin at $37^{\circ} \mathrm{C}$ in a humidified atmosphere of $5 \% \mathrm{CO}_{2}$. These cells were exposed to stimulation with $0,20,50,100$ and $200 \mu \mathrm{M}$ of Form for $2 \mathrm{~h}$.

Adenovirus infection. Adenovirus encoding Ephrin type-B receptor 3 (Ad-EphB3) and green fluorescent protein control (GFP-control) were purchased from Invitrogen (Thermo Fisher Scientific, Inc., Waltham, MA, USA). When HCT116 cells had grown to $70-80 \%$ confluence, the cells were infected by Ad-EphB3 or GFP-control virus (6 MOI) for $24 \mathrm{~h}$ and treated with Form for $12 \mathrm{~h}$. Then cells were collected for assays as previously described (17).

Transfection of miRNA mimics or siRNAs. The human miR-149 mimic and negative control (mimic-NC) were designed and
Table I. Primers used for cell transfection.

\begin{tabular}{ll}
\hline Name & \multicolumn{1}{c}{ Primers (5'-3') } \\
\hline miR-149 & Forward: UCUGGCUCCGUGUCUUCACUCCC \\
& Reverse: GGGAGUGAAGACACGGAGCCAGA \\
mimic-NC Forward: UUCUCCGAACGUGUCACGUTT & Reverse: ACGUGACACGUUCGGAGAATT \\
siEphB3 & Forward: GGACCCUAAUGAGGCUGUU \\
& Reverse: AACAGCCUCAUUAGGGUCC \\
si-NS & Forward: GGAAAUCGAGUUCGCCGUU \\
& Reverse: AACGGCGAACUCGAUUUCC \\
\hline
\end{tabular}

provided by Guangzhou RiboBio Co., Ltd., (Guangzhou, China). The siEphB3 and the negative control RNA (si-NS) were synthesized and purified by Takara Biotechnology Co., Ltd. (Dalian, China). The sequences of miRNAs and siRNAs were described in Table I. Cultured HCT116 and SW620 cells were transfected with miRNAs or siRNAs with the Lipofectamine 2000 reagent (Invitrogen; Thermo Fisher Scientific, Inc.) following the manufacturer's protocol (12).

MTT assay. Following appropriate treatment, the viability of SW1116 and HCT116 cells cultured in 96-well plates was measured using the MTT assay, as previously described (13). Following $24 \mathrm{~h}$, various concentrations $(0,20,50,100$ and $200 \mu \mathrm{M}$ ) of Form were added and incubated for 24,48 , or $72 \mathrm{~h}$. After the media and Form were discarded, the cells were incubated with $0.5 \mathrm{mg} / \mathrm{ml}$ MTT (Sigma-Aldrich; Merck $\mathrm{KGaA}$, Darmstadt, Germany) at $37^{\circ} \mathrm{C}$ for $4 \mathrm{~h}$. The medium was then removed and $150 \mu \mathrm{l}$ DMSO was added to every well. The mixtures were agitated for $15 \mathrm{~min}$ in the dark. The optical density of each well was measured using a microculture plate reader (Omega Bio-Tek, Inc., Norcross, GA, USA) at a wavelength of $490 \mathrm{~nm}$.

Cell cycle analysis. Cells were treated with the Form for $48 \mathrm{~h}$ and harvested by trypsinization, and then cells were washed with ice-cold PBS, fixed with $70 \%$ ethanol at $4^{\circ} \mathrm{C}$ for $24 \mathrm{~h}$, incubated for 5 min with $0.5 \%$ Triton X-100 and stained with propidium iodide at $37^{\circ} \mathrm{C}$ for $30 \mathrm{~min}$ in PBS containing $25 \mathrm{mg} / \mathrm{ml}$ RNase. Stained cells were analyzed by BD ACCURI C6 flow cytometry (BD Biosciences, Franklin Lakes, NJ, USA) and the mean intensity of the cells in each sample was determined by BD Accuri C6 software (BD Biosciences) as previously described (6).

Cell invasion assay. The cell invasion ability was examined using 24-well matrigel-coated Transwell chambers (BD Biosciences) as previously described (6). In brief, the SW1116 and HCT116 cells were treated with Form for $48 \mathrm{~h}$, washed with PBS and resuspended at $1 \times 10^{5}$ cells $/ \mathrm{ml}$ in serum-free medium. Then $0.2 \mathrm{ml}$ cell suspension was added to the upper chamber and $0.5 \mathrm{ml}$ medium containing 10\% FBS was added to the bottom chamber. Following $24 \mathrm{~h}$ incubation, all non-invaded cells were removed from the upper face of the filters and the invaded cells were fixed with $4.0 \%$ paraformaldehyde at room temperature for $15 \mathrm{~min}$ and stained by $0.1 \%$ crystal violet 
A

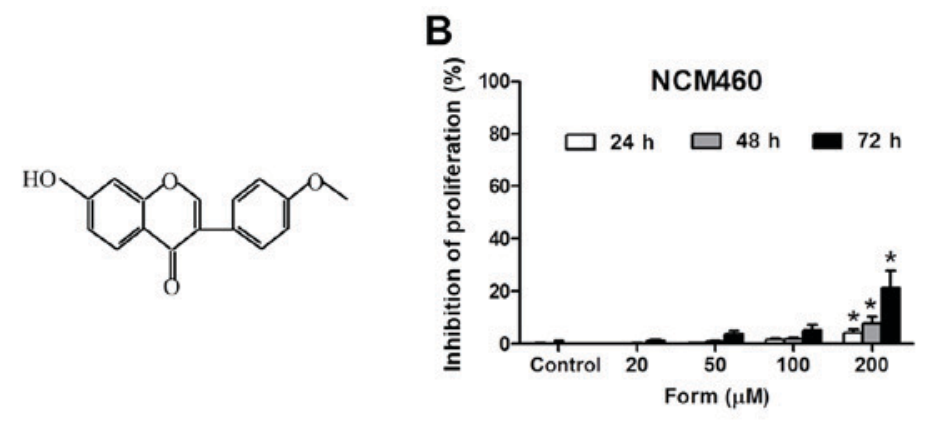

E

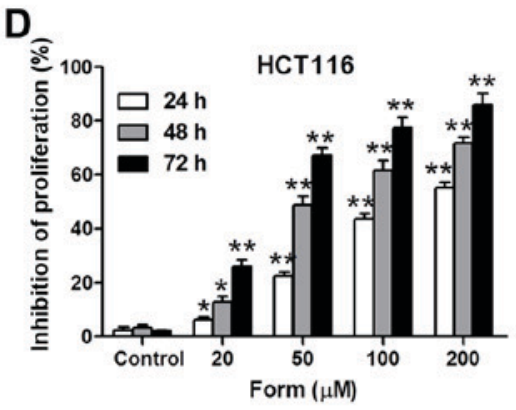

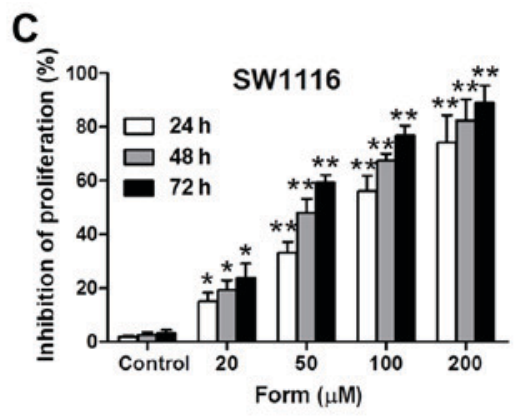

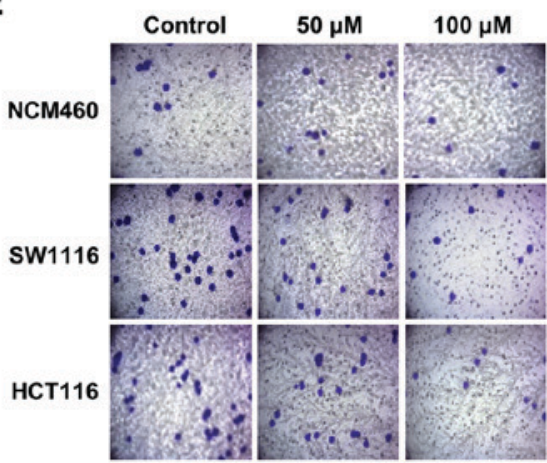

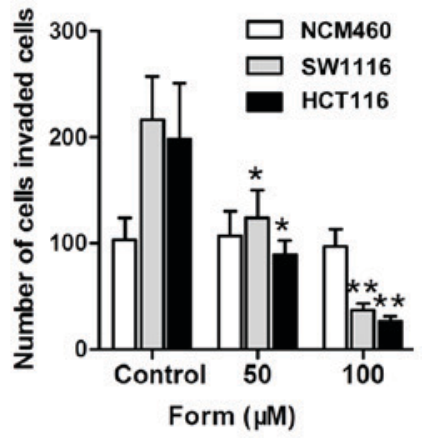

Figure 1. Form inhibits proliferation and invasion of SW1116 and HCT116 cells. (A) The structure of Form. (B) NCM460, (C) SW1116 and (D) HCT116 cells were treated with Form concentrations (0, 20, 50, 100 and $200 \mu \mathrm{M})$ for $48 \mathrm{~h}$. Cell viability was detected using the MTT assay. Five independent experiments were performed. ${ }^{*} \mathrm{P}<0.05$ or ${ }^{* *} \mathrm{P}<0.01$ vs. control $(0 \mu \mathrm{M})$. (E) Transwell assay demonstrated NCM460, SW1116 and HCT116 cells traversed the filter to the other side, stained using crystal violet solution (magnification, $\mathrm{x} 400)$. ${ }^{*} \mathrm{P}<0.05$ or ${ }^{* *} \mathrm{P}<0.01 \mathrm{vs}$. control $(0 \mu \mathrm{M})$. Form, formononetin.

solution at room temperature for $2 \mathrm{~min}$. The experiments were repeated in triplicate wells and the invaded cells were counted using a light microscope (x400) in five different fields of view per filter.

Western blot analysis. The protein concentration of cell lysates of SW1116 and HCT116 by $150 \mathrm{mM} \mathrm{NaCl}, 50 \mathrm{mM}$ Tris- $\mathrm{HCl}$ ( $\mathrm{pH} 7.5$ ), $1 \%$ Nonidet $\mathrm{P}-40,0.5 \%$ sodium deoxycholic acid, and phenylmethane sulfonyl fluoride (78830-1G; Sigma-Aldrich; Merck KGaA) were determined by Coomassie brilliant blue method, then $50 \mathrm{ng}$ protein were separated by $10 \%$ SDS-PAGE and transferred onto a polyvinlidene difluoride membrane (EMD Millipore, Billerica, MA, USA). Membranes were blocked with $5 \%$ milk in $0.1 \%$ Tween-20 TBS for $2 \mathrm{~h}$ at $37^{\circ} \mathrm{C}$ and incubated overnight at $4^{\circ} \mathrm{C}$ with the following primary antibodies: Rabbit anti-cyclin D1 (1:1,000; cat. no. 12363-1-AP; Proteintech Group, Inc., Chicago, IL, USA), rabbit anti-cyclin B1 (1:1,000; cat. no. 21644-1-AP; Proteintech Group, Inc.), rabbit anti-MMP2 (1:1,000; cat. no. 10373-2-AP; Proteintech Group, Inc.) and rabbit anti-MMP9 (1:1,000; cat. no. 10375-2-AP; Proteintech Group, Inc.), mouse anti-phosphorylated (p)-AKT (Ser473; 1:1,000; cat. no. 66444-1-Ig; Proteintech Group, Inc.), mouse anti-AKT (1:1,000; cat. no. 60203-2-Ig; Proteintech Group, Inc.), mouse anti-p-PI3K (Tyr458; 1:1,000; cat. no. 4228T; Cell Signaling Technology, Inc., Danvers, MA, USA), rabbit anti-PI3K (1:1,000; cat. no. 20584-1-AP; Proteintech Group, Inc.), rabbit anti-p-ERK (Thr202/Tyr204; 1:1,000; cat. no. 66192-1-lg; Proteintech Group, Inc.), rabbit anti-ERK (1:1,000; cat. no. 51068-1-AP; Proteintech Group, Inc.), rabbit anti-p-STAT3 (Ser 727; 1:1,000; cat. no. sc-7993; Santa Cruz
Biotechnology, Inc., Dallas, TX, USA), rabbit anti-STAT3 (1:1,000; cat. no. 10253-2-AP; Proteintech Group, Inc.) and rabbit anti- $\beta$-actin (1:5,000; cat. no. 12363-1-AP; Proteintech Group, Inc.). Membranes were washed and incubated with the appropriate horseradish peroxidase-conjugated rabbit anti-mouse secondary antibody (1:1,000; cat. no. 21644-1-AP; Cell Signaling Technology, Inc.). Protein bands were detected by enhanced chemiluminescent plus (Thermo Fisher Scientific, Inc.) and $\beta$-actin was served as an internal control for protein quantitation with cell imaging densitometry (E-Gel GelQuant Express Analysis Software, version 1.7; Thermo Fisher Scientific, Inc.).

RNA isolation and reverse transcription-quantitative polymerase chain reaction $(R T-q P C R)$. Total RNA was extracted from SW1116 and HCT116 cells using the TRizol ${ }^{\mathrm{TM}}$ reagent (Thermo Fisher Scientific, Inc.) according to the manufacturer's protocol. A total $1 \mathrm{mg}$ of RNA was subjected to reverse transcription using first-strand cDNA synthesis kit (Beijing Transgen Biotech Co., Ltd., Beijing, China) according to the manufacturer's protocol. qPCR (SYBR Premix Ex Taq ${ }^{\text {TM }}$; Takara Biotechnology, Co., Ltd.) experiments were carried on an ABI 7500 FAST system (Thermo Fisher Scientific, Inc.). Relative amount of transcripts were normalized with U6 or GAPDH and calculated using the $2^{-\Delta \Delta \mathrm{Cq}}$ formula as previously described (12). All PCRs were performed in triplicate. PCR amplification procedure: $94^{\circ} \mathrm{C}, 5 \mathrm{~min} ;\left(94^{\circ} \mathrm{C}, 30 \mathrm{sec} ; 55^{\circ} \mathrm{C}, 30 \mathrm{sec} ; 72^{\circ} \mathrm{C}\right.$, $1 \mathrm{~min}) \mathrm{x} 30 ; 72^{\circ} \mathrm{C}, 5 \mathrm{~min}$. The primer sequences were as follows: Hsa-miR-149 forward (F), 5'-GGCTCTGGCTCCGTGTCTT-3' and reverse (R), 5'-CAGTGCAGGGTCCGAGGTATT-3'; U6 F, 5'-CAAATTCGTGAAGCGTTCCATA-3' and R, 5'-AGTGCA 
A

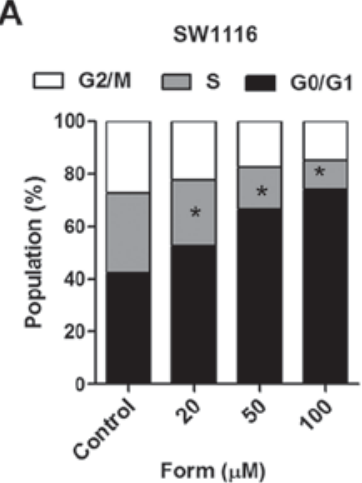

D

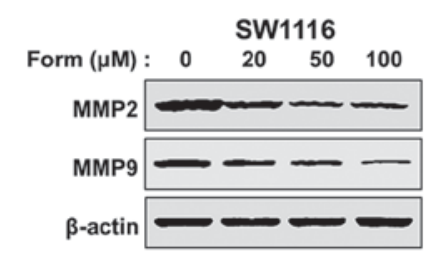

B

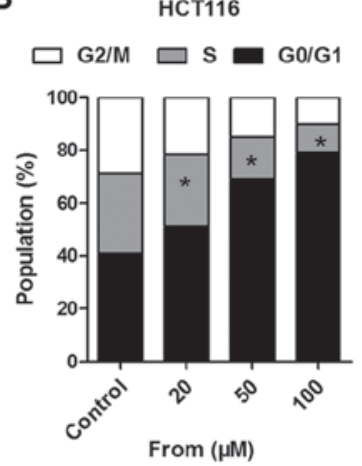

C

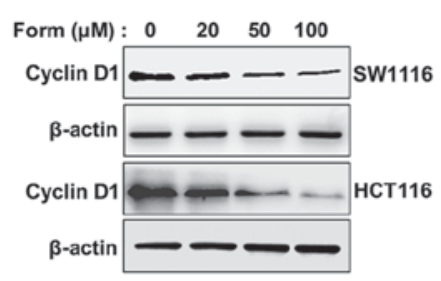

E

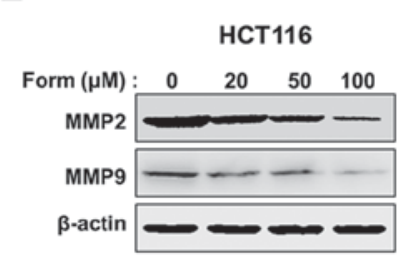

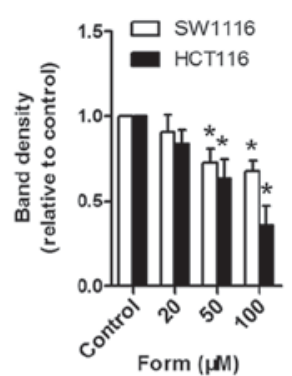

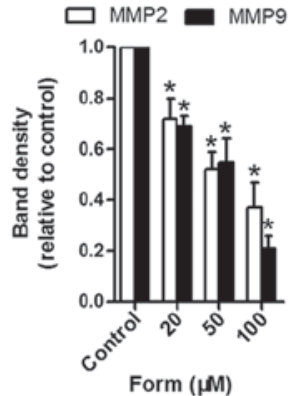

Form ( $\mu \mathrm{M})$

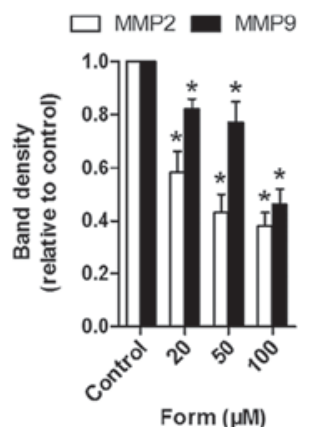

Figure 2. Form induces cell-cycle arrest and inhibits MMP2/9 expression in SW1116 and HCT116 cells. Both (A) SW1116 and (B) HCT116 cells treated with 0, 20,50, and $100 \mu \mathrm{M}$ Form for $48 \mathrm{~h}$ were stained using propidium iodide, and cell-cycle distributions were analyzed using flow cytometry. Bar graph, percentage cells in $\mathrm{G}_{1}, \mathrm{~S}$ and $\mathrm{G}_{2}$ cell-cycle phases. SW1116 and HCT116 cells treated with Form $(0,20,50$, and $100 \mu \mathrm{M})$ for $48 \mathrm{~h}$ and whole-cell extracts collected for the western blot analysis using (C) cyclin D1, (D) MMP2, MMP9, and $\beta$-actin antibodies in SW1116 cells and (E) HCT116 cells. The band intensities relative to $\beta$-actin are presented as the mean \pm standard deviation; $n=6$; ${ }^{P}<0.05$ vs. control. MMP, matrix metalloproteinase; Form, Formononetin.

GGGTCCGAGGTATTC-3'; EphB3 F, 5'-CCTGTACGCCAA CACAGTGC-3' and R, 5'-CTCGAGCCGGATTATATTG-3'; and GAPDH F, 5'-GAAAGCCTGCCGGTGACTAA-3' and R, 5'-GCCCAATACGACCAAATCAGAGA-3'.

Xenograft experiments in vivo. A total of 30 Male BALB/c nude mice, 6-8 weeks, weighting $20-24 \mathrm{~g}$, were purchased from the Experimental Animal Center of Hebei Medical University. The present study was approved by the Laboratory Animal Ethics Committee of Fourth Hospital Hebei Medical University (Shijiazhuang, China). Experimental procedures were implemented according to the guidelines and regulations of the Institutional Animal Care and Use Committee of Hebei Medical University.

The design HCT116 cell numbers $\left(3 \times 10^{8}\right.$ density) were subcutaneously injected into the back of the nude mice. Following the solid tumor growing to $5 \mathrm{~mm}$ in diameter, nude mice were randomly grouped as follows: Vehicle control $(\mathrm{n}=10)$, Form treated groups $(15 \mathrm{mg} / \mathrm{kg}, \mathrm{n}=10)$ and Ad-EhpB3+Form groups $(\mathrm{n}=10)$ intragastrically given $15 \mathrm{mg} / \mathrm{kg}$ daily for 14 days. Tumor size was measured using a digital vernier caliper. The tumor volume was calculated according to the following formula: $\mathrm{mm}^{3}=\mathrm{d}^{2} \mathrm{x} L / 2$, where $\mathrm{d}$ and $\mathrm{L}$ represent the shortest and longest diameters, respectively. The isolated solid tumor was then weighed.

Statistical analysis. All the experiments were repeated three times. The data are presented as the mean \pm standard deviation. The SPSS 13.0 software (SPSS, Inc., Chicago, IL, USA) was used for statistical analyses including analysis of variance and Bonferroni post hoc tests was used for cell viability, cell number, band density, gene expression data and Student's t-test. $\mathrm{P}<0.05$ was considered to indicate a statistically significant difference.

\section{Results}

Form suppresses SW1116 and HCT116 cell proliferation and invasion. The inhibition rates of Form $(0,20,50,100$ and $200 \mu \mathrm{M}$ ) in SW1116 and HCT116 cells and normal epithelial colon NCM460 cells were detected using an MTT assay, and the results suggested that Form inhibited the HCT cell proliferation in a dose- and time-dependent manner (Fig. 1). Compared with the control, the inhibitory effect of Form on SW1116 and HCT116 cells was significantly increased at 24, 48, and $72 \mathrm{~h}(\mathrm{P}<0.05$; Fig. $1 \mathrm{C}$ and $\mathrm{D})$. The Transwell invasion assay performed to examine the effects of Form on SW1116 and HCT116 cell invasiveness demonstrated that Form significantly inhibited the cell invasiveness in a concentration-dependent manner compared with the negative control $(\mathrm{P}<0.05$; Fig. 1E). Overall, these results indicated strong anti-proliferation and anti-invasion effects of Form on SW1116 and HCT116 cells.

Form induces cell-cycle arrest and suppresses cell invasion in SW1116 and HCT116 cells. Flow cytometry was performed to assess the cell cycle in the 4 groups (control, 20, 50 and $100 \mu \mathrm{M}$ Form) to further elucidate how Form inhibits SW1116 and HCT116 cell proliferation. Cells treated with different Form concentrations $(20,50$ and $100 \mu \mathrm{M})$ for $48 \mathrm{~h}$ increased the proportion in the $\mathrm{G}_{0}-\mathrm{G}_{1}$ phase compared with the control 
A

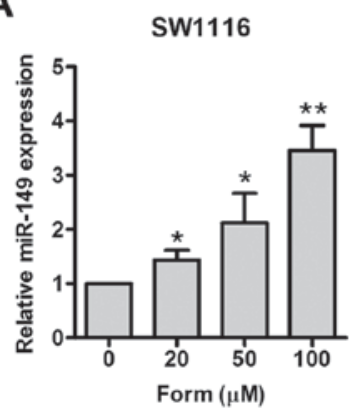

C

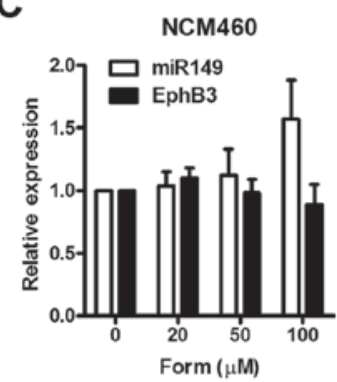

HCT116

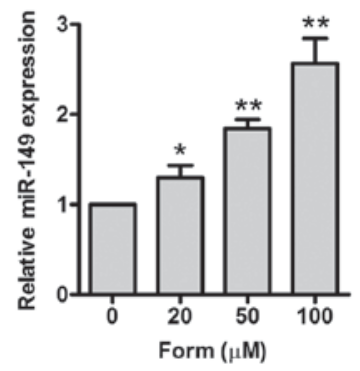

B

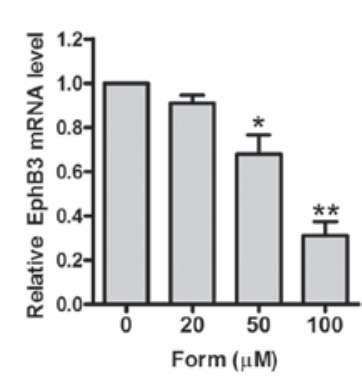

HCT116

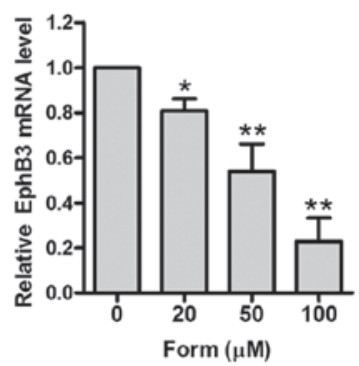

D
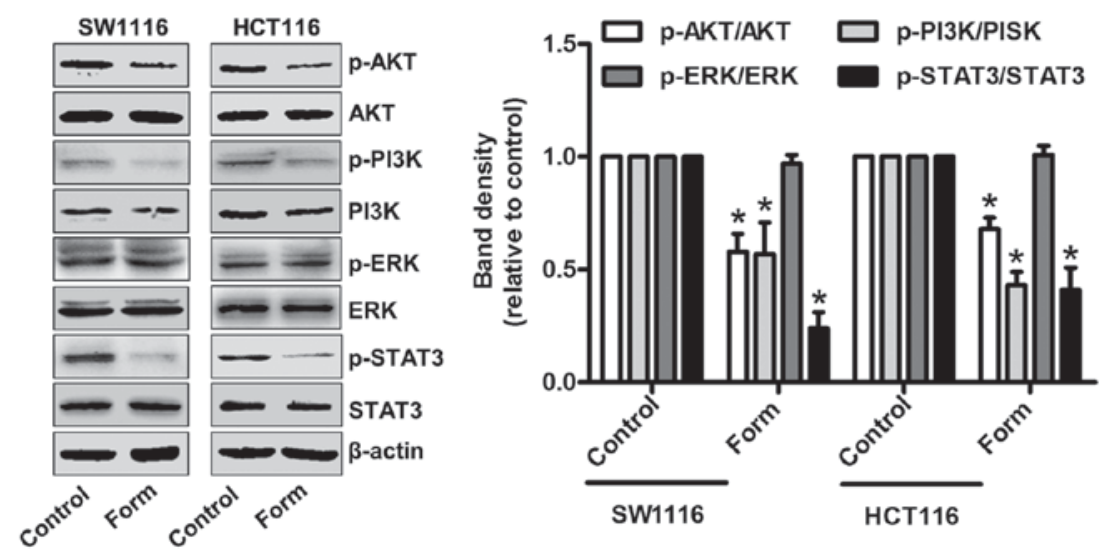

Figure 3. Form regulates miR-149 and EphB3 expression and suppresses AKT/PI3K expression and STAT3 signaling in SW1116 and HCT116 cells. (A) SW1116, (B) HCT116 and (C) NCM460 cells were treated with Form $(20,50$, and $100 \mu \mathrm{M})$ for 48 h, then miR-149 and EphB3 mRNA were determined using reverse transcription-quantitative polymerase chain reaction. Data are expressed as the mean \pm standard deviation. ${ }^{*} \mathrm{P}<0.05$ and ${ }^{* *} \mathrm{P}<0.01$ vs. control, $\mathrm{n}=5$. (D) $\mathrm{SW} 1116$ and HCT116 cells were incubated with Form $(100 \mu \mathrm{M})$ for $12 \mathrm{~h}$, and the protein levels of p- and total PI3K, AKT, ERK, and STAT3 were determined using western blotting. The band intensities relative to AKT, PI3K, ERK and STAT3 are presented as the mean \pm standard deviation. ${ }^{*} \mathrm{P}<0.05$ vs. the control; $\mathrm{n}=6$. Form, Formononetin; p-PI3K, phosphorylated-phosphoinositide 3 kinase; AKT, protein kinase B; ERK, extracellular regulated signal kinase; STAT3, signal transducer and activator of transcription 3; EphB3, Ephrin type-B receptor 3.

$(\mathrm{P}<0.05)$; the proportion of cells undergoing this phase increased to $79.7 \%$ following treatment with $100 \mu \mathrm{M}$ Form $(\mathrm{P}<0.05$; Fig. 2A and B). Form was also observed to suppress cyclin D1 but not cyclin B1 expression (data not shown) in a dose-dependent manner (Fig. 2C). The expression of extracellular matrix-degrading enzymes MMP2 and MMP9, which serve roles in cell invasion regulation, were examined to delineate the mechanism by which Form protects human colon carcinoma cell invasion (18). Fig. 2D and E demonstrates that Form treatment significantly attenuated MMP2 and MMP9 protein expression, as determined using western blotting analysis. These results indicate that the suppressive effects of Form on human colon carcinoma cell proliferation and invasion are mediated by the inhibition of cyclin D1 and MMP2/MMP9 expressions.

Form regulates the expression of miR-149 and EphB3 and the phosphorylation of Akt/PI3K and STAT3 in SW1116 and HCT116 cells. A recent study has demonstrated the suppressive role of the EphB3-targeted miR-149 regulation in the migration and invasion of human colon carcinoma (12). Therefore, the present study aimed to determine the inhibitory effects of Form on SW1116 and HCT116 cells and whether different Form concentrations altered miR-149 and EphB3 (the direct target of miR-149) expression. Fig. 3A indicates that Form upregulated miR-149 expression in SW1116 and HCT116 cells compared with untreated cells in a dose-dependent manner $(\mathrm{P}<0.05$ and $\mathrm{P}<0.01)$. Although the EphB3 mRNA expression was significantly downregulated $(\mathrm{P}<0.05$ and $\mathrm{P}<0.01$; Fig. $3 \mathrm{~B})$ when treated with Form, miR-149 and EphB3 expression demonstrated no apparent alterations in normal epithelial colon NCM460 cells (Fig. 3C). In addition, the ERK, AKT, PI3K and STAT3 signaling pathways have been implicated in the regulation of cell proliferation, and invasion, in addition to cell cycle-associated protein and MMP expression (19-21). Therefore, the roles of p-ERK, p-AKT, p-PI3K and p-STAT3 signaling in SW1116, and HCT116 cells were investigated following treatment with Form. Fig. 3D indicated that Form treatment significantly decreased p-AKT, p-PI3K and p-STAT3 protein expression compared with the control, suggesting that Form alters p-AKT, p-PI3K, and p-STAT3 protein levels in SW1116 and HCT116 cells $(\mathrm{P}<0.05)$. However, the total protein levels of AKT, PI3K, STAT3 and ERK signaling remained unaffected. These data suggested that Form suppresses cell proliferation and invasion by inhibition of cyclin D1 and MMP2/9 expression via p-AKT, p-PI3K, and p-STAT3 inactivation in colon carcinoma cells. These data indicate that Form significantly upregulates miR-149 expression, downregulates EphB3 and inhibits PI3K/AKT and STAT3 phosphorylation in SW1116 and HCT116 cells. 
A

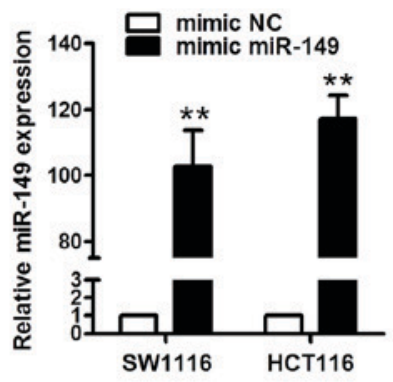

B

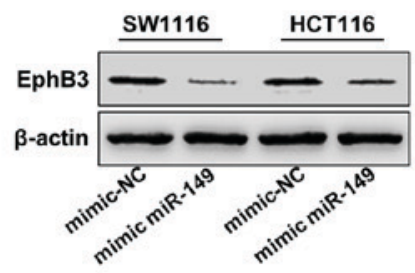

C

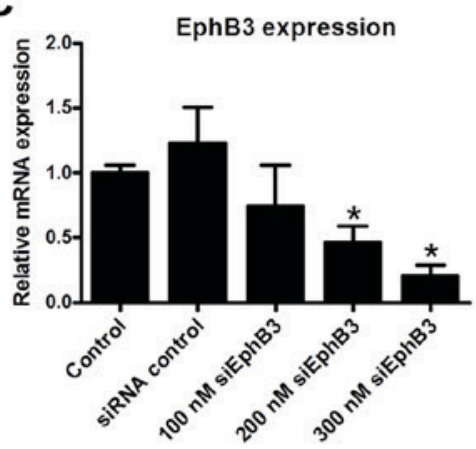

D

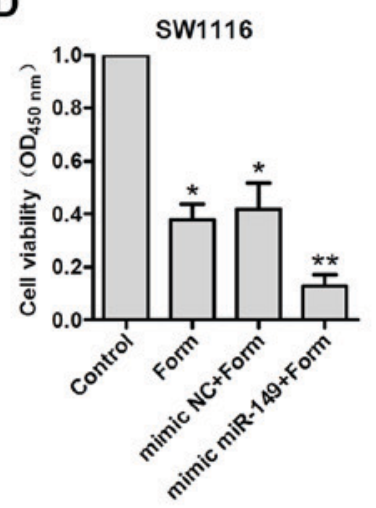

F

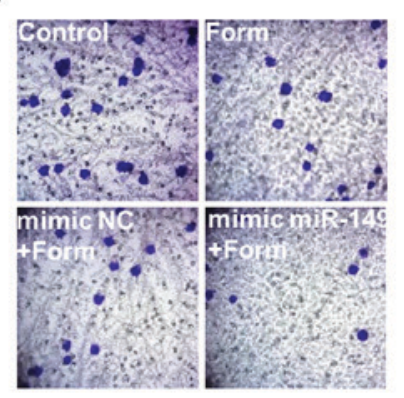

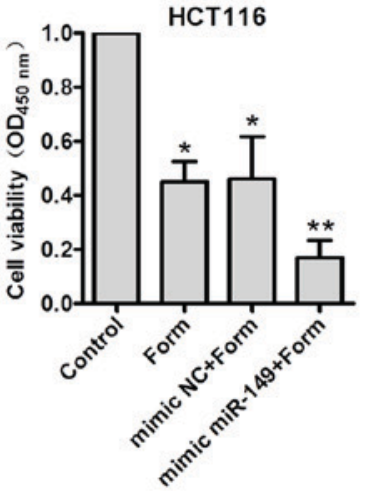

E
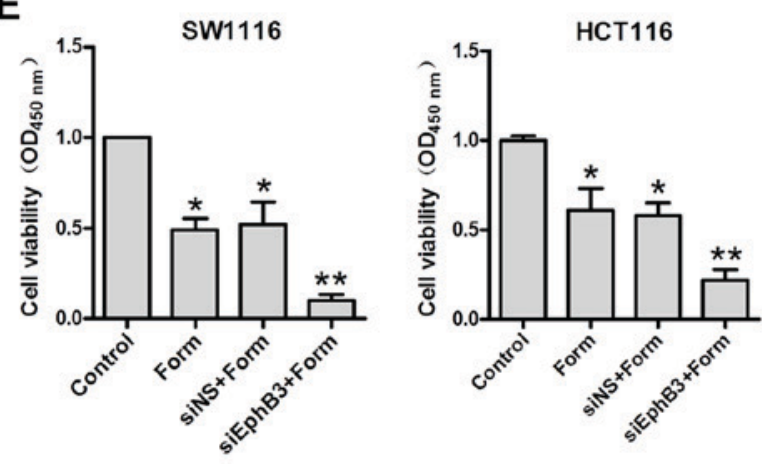

G

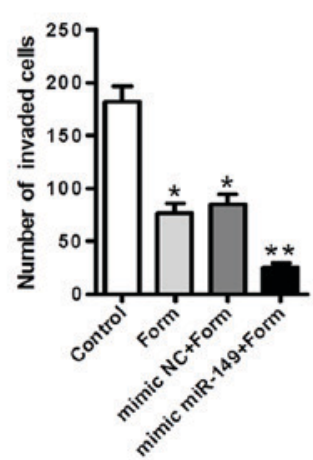

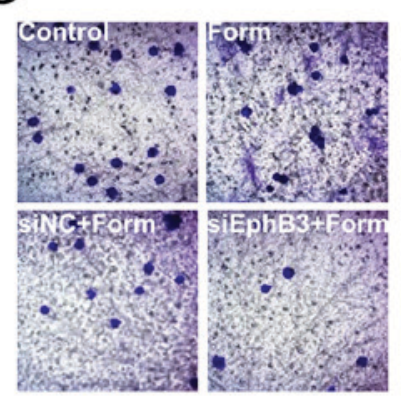

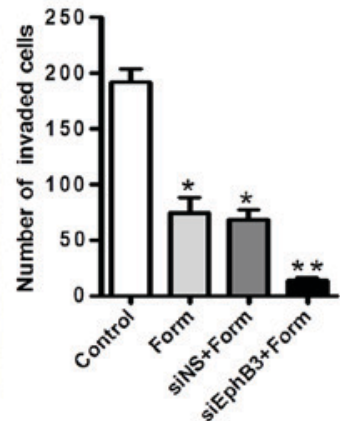

Figure 4. Both the mimic miR-149 and siEphB3 enhance Form-induced inhibition of proliferation of colon cancer cells. (A) RT-qPCR analysis of miR-149 in SW1116 and HCT116 cells transfected with mimic miR-149 or negative control. Data are depicted as the mean \pm standard deviation. ${ }^{* *} \mathrm{P}<0.01 \mathrm{vs}$. control, $\mathrm{n}=5$. (B) Western blot analysis for EphB3 expression detection in SW1116 and HCT116 cells transfected with mimic miR-149. (C) RT-qPCR for siRNA-mediated silencing verification of EphB3 mRNA in SW1116 and HCT116 cells transfected with siEphB3 or siRNA control. ${ }^{\mathrm{P}}<0.05$ vs. control, $\mathrm{n}=5$. SW1116 and HCT116 cells transfected with (D) mimic-NC or mimic miR-149 for $24 \mathrm{~h}$ or transfected with (E) siEphB3 or siNS for $24 \mathrm{~h}$. Transfected cells were then treated with $100 \mu \mathrm{M}$ Form for $24 \mathrm{~h}$. Cell viability was determined using the MTT assay. Data are illustrated as the mean \pm standard deviation, ${ }^{*} \mathrm{P}<0.05$ and ${ }^{* *} \mathrm{P}<0.01 \mathrm{vs}$. control, $n=5$. (F) Transwell assay demonstrated that miR-149 overexpression and (G) EphB3 downregulation enhanced Form-inhibited cell invasion in HCT116 cells (magnification, $\mathrm{x} 400$ ). Data are presented as the mean \pm standard deviation, ${ }^{*} \mathrm{P}<0.05$ and ${ }^{* *} \mathrm{P}<0.01$ vs. the control, $\mathrm{n}=5$. RT-qPCR, reverse transcription-quantitative polymerase chain reaction; si, small interfering; miR, microRNA; NS, normal control; EphB3, Ephrin type-B receptor 3; Form, Formononetin.

Ectopic miR-149 expression and small interfering (siRNA)-mediated EphB3 silencing promotes Form-inhibition of cell growth and invasion in SW1116 and HCT116 cells. To elucidate the role of miR-149 and EphB3 in Form-inhibited cell growth and invasion in colon carcinoma cells, SW1116 and HCT116 cells were transiently transfected with an miR-149 mimic, miR-149 mimic control (mimic-NS), or EphB3 siRNA for EphB3 expression knockdown, and its efficacy was confirmed using RT-qPCR and western blot analysis. The results of RT-qPCR revealed that the miR-149 mimic significantly upregulated the miR-149 expression in SW1116 and HCT116 cells compared with the mimic-NS
(P<0.01; Fig. 4A). SW1116 and HCT116 cells transfected with miR-149 mimic demonstrated lower EphB3 expression levels compared with the mimic control groups, as determined using western blot analysis (Fig. 4B). Different siRNA concentrations were used in both cell lines to standardize the conditions and inhibit expression of EphB3 (Fig. 4C). Based on the obtained results, SW1116 and HCT116 cells were transfected with the miR-149 mimic, mimic-NS, siNS, or EphB3 siRNA, and following $24 \mathrm{~h}$, they were treated with Form for $2 \mathrm{~h}$. The results revealed that cell viability was significantly decreased in the mimic miR-149+Form group compared with the other 3 groups $(\mathrm{P}<0.01$; Fig. 4D); Cell viability was also significantly 
A

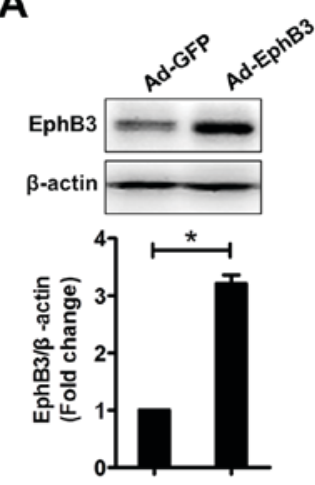

B

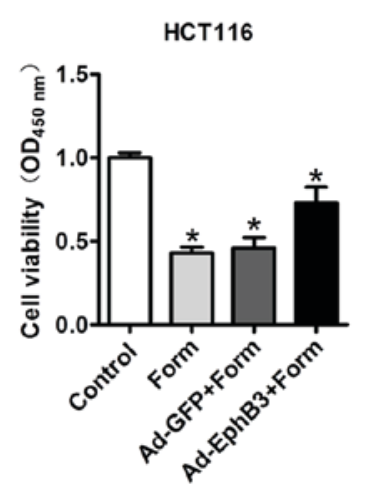

C

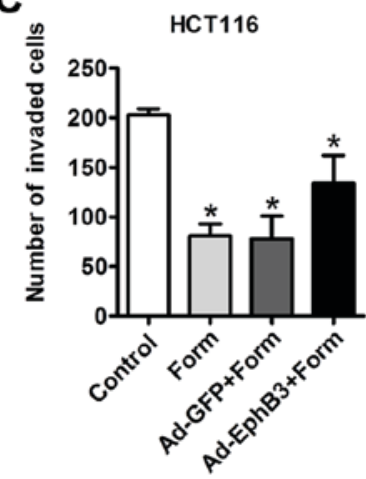

D

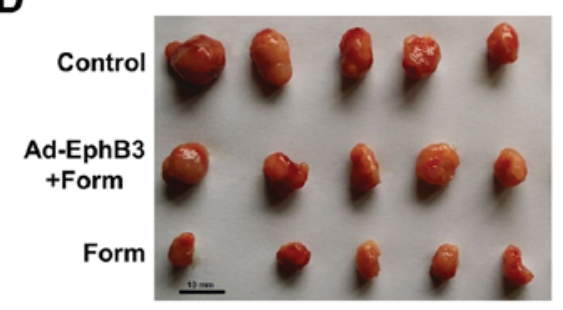

E

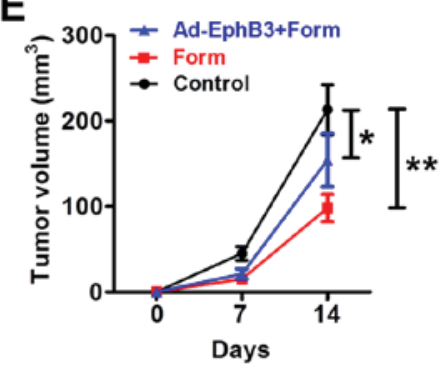

$\mathbf{F}$

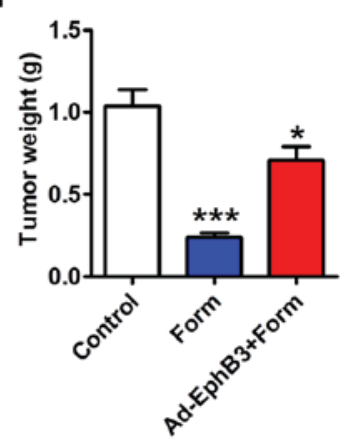

Figure 5. EphB3 overexpression by Ad-EphB3 partially decreased Form-induced inhibition of cell viability and invasion in colon cancer cells. HCT116 cells were infected with the Ad-GFP control or Ad-EphB3, $24 \mathrm{~h}$ following infection cells were treated with $100 \mu \mathrm{M}$ Form for $24 \mathrm{~h}$. (A) The expression of EphB3 was analyzed by western blotting. (B) MTT assay and (C) Transwell assay were performed to determine cell viability and invasion. Data are presented as the mean \pm standard deviation, ${ }^{*} \mathrm{P}<0.05$ vs. the Control, $\mathrm{n}=5$. Ad-GFP, adenovirus-green fluorescent protein; EphB3, Ephrin type-B receptor 3; Form, Formononetin. (D) HCT116 (Control), Form treatment and Ad-EphB3 infection and Form treatment (Ad-EphB3+Form) xenograft tumour masses were harvested on day 28. Photographs of tumor removed from mice in each group. (E) Form treatment significantly decreased and Ad-EphB3+Form rescued the xenograft tumour volumes and (F) tumor weights, compared with Control. ${ }^{*} \mathrm{P}<0.05,{ }^{* *} \mathrm{P}<0.01,{ }^{* * * *} \mathrm{P}<0.001$ vs. the Control.

decreased in the siEphB3+Form group compared to the other 3 groups $(\mathrm{P}<0.01$; Fig. $4 \mathrm{E})$, suggesting a role EphB3 in Form-inhibited colon carcinoma cell growth. Similarly, Transwell assays indicated that Form induced the inhibition of HCT116 cell invasion where miR-149 overexpression or EphB3 knockdown significantly increased compared with the negative control $(\mathrm{P}<0.05$; Fig. $4 \mathrm{~F}$ and $\mathrm{G})$. These results indicated the role of miR-149 and EphB3 in the Form-inhibited cell growth and invasion in colon carcinoma cells.

EphB3 overexpression partially decreases the Form-inhibited colon carcinoma cell growth. The EphB3 expression was enhanced using Ad-EphB3 in HCT116 cells to elucidate the role of miR-149 and EphB3 in Form-inhibited cell growth and invasion in colon carcinoma cells. In Fig. 5A-C, the western blot analysis demonstrated that Ad-EphB3 infection enhanced EphB3 expression in HCT116 cells and that its overexpression could rescue Form-inhibited cell viability and invasion. The effects of Form on colon carcinoma cell growth in xenograft nude mice were analyzed to confirm the in vitro results. As illustrated in Fig. 5D-F, xenograft nude mice treated by subcutaneous injection for 2 weeks demonstrated a significant increase in tumor volume and weight, whereas Form significantly reduced growth of tumor xenografts compared with the control $(\mathrm{P}<0.05)$. Furthermore, the suppressive effects of
Form on colon cancer cell growth could be partially abolished by overexpressing EphB3. These results indicated the role of EphB3 in the Form-inhibited colon carcinoma cell growth.

\section{Discussion}

The present study aimed to elucidate the molecular mechanisms of Form and its inhibitory effect exerted on the proliferation and invasion of colon carcinoma cells in vitro. It was demonstrated that Form inhibits colon carcinoma cell proliferation and invasion by suppressing cyclin D1 and MMP2/9 expression via miR-149-induced EphB3 downregulation, and downregulates PI3K/AKT activity and STAT3 signaling pathways.

The anticarcinogenic activities of different herbal flavonoids may involve both common and novel mechanisms of action, which could be developed into potential anticancer drugs. Form, a traditional Chinese herbal medicine isolated from red clover, not only possesses a number of properties, including antioxidant, antiviral and cardioprotective effects, but is also gaining prominence for its potential antitumor effect (22). Previous studies have demonstrated that Form exerts anticarcinogenic effects on cancer cells by miR-mediated target gene regulation and associated signaling pathways (9). Furthermore, a recent study has highlighted that EphB3 is a direct target gene for miR-149 and regulates colon carcinoma 
cell development, including cell proliferation, invasion, and cell cycle progression, via EphB3 expression regulation (12). The present study demonstrated that Form dose-dependently upregulated miR-149 expression and downregulated EphB3 mRNA expression in SW1116 and HCT116 cells. These results were in agreement with those of previous studies that demonstrated variable expression patterns of miR-149 and its target gene in colorectal cancer cells $(23,24)$. A role of miR-149 and EphB3 in Form-inhibited cell growth and invasion in colon carcinoma cells was demonstrated.

Additionally, previous studies have reported that Form can attenuate the growth and invasion of various cancer cell types and suppress cyclin and MMP expression by inhibiting a number of mitogen-activated protein kinase pathways, including the ERK1/2, p38, JNK (25), PI3K/AKT, and STAT3 pathways (26). Furthermore, cyclin D1 and MMP2/9 expression was demonstrated to decrease in SW1116 and HCT116 cells treated with Form and that cyclin D1 and MMP2/9 mediated Form-elicited SW1116 and HCT116 cell growth and invasion through PI3K/AKT signaling pathways. These results corroborate those of previous studies demonstrating that Form promoted cell-cycle arrest and invasion via AKT/cyclin D1/STAT3 downregulation in breast (6) and prostate cancer cells (5). Particularly, Form treatment was demonstrated to inhibit CRC proliferation and invasion by suppressing cyclin D1 and MMP2/9 expression via PI3K/AKT downregulation and STAT3 signaling pathways.

Accumulating evidence suggests that cyclin D1 is essential in cell-cycle control and that its expression is regulated by PI3K/AKT (27). A previous study highlighted the role of cyclin D1 in several human cancers, including breast cancer (15). SW1116 and HCT116 cells both treated with Form were demonstrated to accumulate at the $\mathrm{G}_{0}-\mathrm{G}_{1}$ phase. Form significantly stimulated p-PI3K/AKT signaling pathway inactivation and decreased cyclin D1 expression, which is consistent with the MTT assay results. These results indicated that Form inhibited SW1116 and HCT116 cell growth by suppressing cyclin D1 expression, which promotes cell-cycle arrest through PI3K/AKT signaling pathway inactivation.

In colon cancer, tumor cells must invade the muscularis mucosa and migrate into the submucosa prior to reaching the lymphatic channels or blood vessels. This proteolytic degradation of the extra cellular membrane by proteolytic enzymes like MMP2/9 is a necessary step in cancer metastasis. MMP2/9 expression is mediated by the PI3K/AKT signaling pathway. STAT3 is a well-known MMP inducer as well as a downstream component of the PI3K/AKT pathway. p-STAT3 is translocated into the nucleus to transmit extracellular signals that regulate tumor cell proliferation and migration (28). PI3K/AKT and STAT3 inactivation as well as a decrease in the extracellular MMP2/9 expression in SW1116 and HCT116 cells, were observed upon cell treatment with Form, which inhibited tumor growth and invasion. In accordance with the results of the present study, Huang et al (13) reported the antiproliferative effects of Form on human CRC through the suppression of cell growth and invasion both in vitro and in vivo. In addition, Zhang et al (12) reported that the EphB3-targeted regulation of miR-149 served a suppressive role in the migration and invasion of human colonic carcinoma. Although it was confirmed that Form affected the expression of miR-149 and the EphB3 gene in SW1116 and HCT116 cells, there remains a question as to how miR149 regulates the expression of MMP and cyclin D in the present study, which should be the focus of a future study. Overall, these results suggest that Form inhibits tumor growth and cell invasion, thereby highlighting its potential for use in advanced and metastatic colon cancer treatment.

\section{Acknowledgements}

Not applicable.

\section{Funding}

No funding was received.

\section{Availability of data and materials}

The datasets used and analyzed during the current study are available from the corresponding author on reasonable request.

\section{Authors' contributions}

ALW carried out the experimental work, and data collection and interpretation. YL participated in the design and coordination of experimental work, and the acquisition of data. QZ participated in the study design, data collection, analysis of data and preparation of the manuscript. LQF carried out the study design, the analysis and interpretation of data, and drafted the manuscript. All authors read and approved the final manuscript.

\section{Ethics approval and consent to participate}

The present study was approved by the Labratory Animal Ethics Committee of Fourh Hospital Hebei Medical University (Shijiazhuang, China). Experimental procedures were implemented in according to the guidelines and regulations of the Institutional Animal Care and Use Committee of Hebei Medical University.

\section{Consent for publication}

Not applicable.

\section{Competing interests}

The authors declare that there are no competing interests.

\section{References}

1. Bodalal Z and Bendardaf R: Coloectal carcinoma in aSouthern Mediterranean country: The Libyan scenario. World J Gastrointest Oncol 6: 98-103, 2014.

2. Touil Y, Igoudjil W, Corvaisier M, Dessein AF, Vandomme J, Monté D, Stechly L, Skrypek N, Langlois C, Grard G, et al: Colon cancer cells escape 5FU chemotherapy-induced cell death by entering stemness and quiescence associated with the c-Yes/YAP axis. Clin Cancer Res 20: 837-846, 2014.

3. Misale S, Yaeger R, Hobor S, Scala E, Janakiraman M, Liska D, Valtorta E, Schiavo R, Buscarino M, Siravegna G, et al: Emergence of KRAS mutations and acquired resistance to anti-EGFR therapy in colorectal cancer. Nature 486: 532-536, 2012. 
4. Jin M, Zhao K, Huang Q and Shang P: Structural features and biological activities of the polysaccharides from Astragalus membranaceus. Int J Biol Macromol 64: 257-266, 2014.

5. Li T, Zhao X, Mo Z, Huang W, Yan H, Ling Z and Ye Y: Formononetin promotes cell cycle arrest via downregulation of Akt/Cyclin D1/CDK4 in human prostate cancer cells. Cell Physiol Biochem 34: 1351-1358, 2014.

6. Zhou R, Xu L, Ye M, Liao M, Du H and Chen H: Formononetin inhibits migration and invasion of MDA-MB-231 and 4T1 breast cancer cells by suppressing MMP-2 and MMP-9 through PI3K/AKT signaling pathways. Horm Metab Res 46: 753-760, 2014.

7. Barbato S, Solaini G and Fabbri M: MicroRNAs in oncogenesis and tumor suppression. Int Rev Cell Mol Biol 333: 229-268, 2017.

8. Lewis BP, Shih IH, Jones-Rhoades MW, Bartel DP and Burge CB: Prediction of mammalian microRNA targets. Cell 115: 787-798, 2003.

9. Wu Y, Zhang X, Li Z, Yan H, Qin J and Li T: Formononetin inhibits human bladder cancer cell proliferation and invasiveness via regulation of miR-21 and PTEN. Food Funct 8: 1061-1066, 2017.

10. $\mathrm{Hu} \mathrm{W}$ and Xiao Z: Formononetin induces apoptosis of human osteosarcoma cell line U2OS by regulating the expression of Bcl-2, Bax and MiR-375 in vitro and in vivo. Cell Physiol Biochem 37: 933-939, 2015.

11. Chen J, Zhang X, Wang Y, Ye Y and Huang Z: Formononetin promotes proliferation that involves a feedback loop of microRNA-375 and estrogen receptor alpha in estrogen receptorpositive cells. Mol Carcinog 55: 312-319, 2016.

12. Zhang G, Liu X, Li Y, Wang Y, Liang H, Li K, Li L, Chen C, Sun W, Ren S, et al: EphB3-targeted regulation of miR-149 in the migration and invasion of human colonic carcinoma HCT116 and SW620 cells. Cancer Sci 108: 408-418, 2017.

13. Huang J, Xie M, Gao P, Ye Y, Liu Y, Zhao Y, Luo W, Ling Z, Cao Y, Zhang S, et al: Antiproliferative effects of formononetin on human colorectal cancer via, suppressing cell growth in vitro, and in vivo. Process Biochem 50: 912-917, 2015.

14. Auyeung KK, Law PC and Ko JK: Novel anti-angiogenic effects of formononetin in human colon cancer cells and tumor xenograft. Oncol Rep 28: 2188-2194, 2012.

15. Chen J, Zeng J, Xin M, Huang W and Chen X: Formononetin induces cell cycle arrest of human breast cancer cells via IGF1/PI3K/Akt pathways in vitro and in vivo. Horm Metab Res 43: 681-686, 2011.

16. Begnini KR, Moura de Leon PM, Thurow H, Schultze E, Campos VF, Martins Rodrigues F, Borsuk S, Dellagostin OA, Savegnago L, Roesch-Ely M, et al: Brazilian red propolis induces apoptosis-like cell death and decreases migration potential in bladder cancer cells. Evid Based Complement Alternat Med 2014: 639856, 2014

17. Li G, Ji XD, Gao H, Zhao JS, Xu JF, Sun ZJ, Deng YZ, Shi S, Feng YX, Zhu YQ, et al: EphB3 suppresses non-small-cell lung cancer metastasis via a PP2A/RACK1/Akt signalling complex. Nat Commun 3: 667, 2012.
18. Chen $\mathrm{J}$ and Sun L: Formononetin-induced apoptosis by activation of Ras/p38 mitogen-activated protein kinase in estrogen receptor-positive human breast cancer cells. Horm Metab Res 44 943-948, 2012

19. Galliher AJ and Schiemann WP: Src phosphorylates Tyr284 in TGF-beta type II receptor and regulates TGF-beta stimulation of p38 MAPK during breast cancer cell proliferation and invasion. Cancer Res 67: 3752-3758, 2007.

20. Sun M, Liu C, Nadiminty N, Lou W, Zhu Y, Yang J, Evans CP, Zhou Q and Gao AC: Inhibition of Stat3 activation by sanguinarine suppresses prostate cancer cell growth and invasion. Prostate 72: 82-89, 2012.

21. Ko JK, Lam FY and Cheung AP: Amelioration of experimental colitis by Astragalus membranaceus through anti-oxidation and inhibition of adhesion molecule synthesis. World J Gastroenterol 11: 5787-5794, 2005.

22. Auyeung KK and Ko JK: Novel herbal flavonoids promote apoptosis but differentially induce cell cycle arrest in human colon cancer cell. Invest New Drugs 28: 1-13, 2010.

23. Wang F, Ma YL, Zhang P, Shen TY, Shi CZ, Yang YZ, Moyer MP, Zhang HZ, Chen HQ, Liang Y and Qin HL: SP1 mediates the link between methylation of the tumour suppressor miR-149 and outcome in colorectal cancer. J Pathol 229: 12-24, 2013.

24. Liu X, Xie T, Mao X, Xue L, Chu X and Chen L: MicroRNA-149 increases the sensitivity of colorectal cancer cells to 5-fluorouracil by targeting forkhead box transcription factor FOXM1. Cell Physiol Biochem 39: 617-629, 2016.

25. Wu XY, Xu H, Wu ZF, Chen C, Liu JY, Wu GN, Yao XQ, Liu FK, Li G and Shen L: Formononetin, a novel FGFR2 inhibitor, potently inhibits angiogenesis and tumor growth in preclinical models. Oncotarget 6: 44563-44578, 2015.

26. Nicholson KM and Anderson NG: The protein kinase B/Akt signaling pathway in human malignancy. Cell Signal 14: 381-395, 2002.

27. Liabakk NB, Talbot I, Smith RA, Wilkinson K and Balkwill F: Matrix metalloprotease 2 (MMP-2) and matrix metalloprotease 9 (MMP-9) type IV collagenases in colorectal cancer. Cancer Res 56: 190-196, 1996.

28. Timofeeva OA, Tarasova NI, Zhang X, Chasovskikh S, Cheema AK, Wang H, Brown ML and Dritschilo A: STAT3 suppresses transcription of proapoptotic genes in cancer cells with the involvement of its N-terminal domain. Proc Natl Acad Sci USA 110: 1267-1272, 2013.

This work is licensed under a Creative Commons Attribution-NonCommercial-NoDerivatives 4.0 International (CC BY-NC-ND 4.0) License. 